\title{
Factors influencing oocyte and embryo quality in cattle
}

\author{
Patrick LONERGAN*, Dimitrios RIzos, Fabian WARD, \\ Maurice P. BOLAND

\begin{abstract}
Department of Animal Science / Production and Conway Institute Lyons Research Farm, Newcastle, County Dublin, Ireland
\end{abstract} \\ for Biomedical and Biomolecular Research, University College Dublin,
}

(Received 15 October 2001; accepted 5 November 2001)

\begin{abstract}
Following in vitro maturation, approximately 90\% of immature bovine oocytes will reach metaphase II and extrude the first polar body; approximately $80 \%$ will undergo fertilization and cleave, at least once, to the two-cell stage. However, only about 30-40\% will ever reach the blastocyst stage. This would suggest that the post-fertilization part of the process of in vitro embryo production, the longest part, is the main period determining blastocyst yield. The experiments described in this paper clearly demonstrate that this is, in fact, not the case and that it is events further back along the developmental axis that determine the proportion of immature oocytes reaching the blastocyst stage. The results also show, however, that the post-fertilization culture period is of profound importance in determining the equality of those blastocysts that do develop, with those produced in vitro consistently being of inferior quality to their in vivo produced conterparts. The challenge for the future is to modify our conditions of post-fertilization embryo culture in an attempt to mimic those that occur naturally in vivo and in that way improve blastocyst quality.
\end{abstract}

Cattle / oocyte competence / embryo quality / cryopreservation

\section{INTRODUCTION}

While conditions of culture during the various steps of in vitro embryo production (IVP) can undoubtedly affect developmental rates, the relatively low level of efficiency achieved, manifested by the frequent failure of up to $60 \%$ of immature oocytes to reach the blastocyst stage, is almost certainly related to the intrinsic quality of the oocyte at the beginning of maturation.

In addition to the proportion of oocytes developing to the blastocyst stage, the quality of these embryos is important. Despite extensive research in terms of increasing the yield of blastocysts from immature

\footnotetext{
* Correspondence and reprints

E-mail: lonergan@pop3.ucd.ie
} 
oocytes, the quality of in vitro-produced embryos, in terms of survival following cryopreservation, has continually lagged behind that achieved with in vivo-derived embryos. The aim of this paper is to briefly review the literature in relation to the factors controlling both blastocyst yield and blastocyst quality in cattle as well as describing some recent findings from our own laboratory.

\section{DEFINITIONS OF OOCYTE AND EMBRYO QUALITY}

It is important to distinguish between the terms "oocyte quality" and "embryo quality". The ultimate test of the quality of an oocyte is its ability to be fertilized and develop to the blastocyst stage, to establish a pregnancy and ultimately to produce a live calf. Similarly, the best measure of blastocyst quality is the ability to establish a pregnancy and produce a calf. Unfortunately, in most instances we do not have the luxury of transferring every blastocyst produced from IVP. Therefore, we have to settle for using parameters such as cleavage and blastocyst production as the best measures of oocyte quality. With regard to embryo quality, as pointed out by Bavister [7], the selection of the "best" blastocysts from a pool for transfer may not be indicative of the quality of that entire population. From a laboratory point of view, one useful measure of quality is the ability of the embryo to survive cryopreservation, as essentially all embryos from a given treatment can be tested.

\section{PARAMETERS USED TO ASSESS QUALITY - IMPORTANCE OF THE KINETICS OF EARLY CLEAVAGE DIVISIONS}

We have previously demonstrated a clear relationship between the time of first cleavage post-insemination in vitro and developmental competence, with those oocytes cleaving earliest after IVF being more likely to reach the blastocyst stage than their latercleaving counterparts $[18,48]$. This phenomenon is common to many species [8, $54,69,71,78,84]$. In addition we have demonstrated that this timing of first cleavage is related to the polyadenylation status of several developmentally important gene transcripts [12]. Subsequently, we demonstrated differences in gene expression in the early embryo that are reflective of differences in developmental competence between early- and late-cleaving zygotes [51]. The factors that control the time of first cleavage are unclear. Although culture conditions can influence the kinetics of early development $[42,62]$, it is likely that the main factors controlling this parameter are intrinsic to the oocyte $[12,48,51]$, the sperm $[15,21,83]$ or both. Indeed, in mice, a gene controlling the rate of preimplantation cleavage division and subsequent embryo survival (Ped: preimplantation embryo development) has been identified [84].

\section{DIFFERENCES BETWEEN IN VIVO- AND IN VITRO-PRODUCED EMBRYOS}

Differences between in vivo- and in vitroderived embryos have been reviewed by several authors $[53,87]$. These differences include darker cytoplasm, lower density [64], more lipids, specifically, more triglycerides and less lipids from other classes [1], swollen blastomeres [81], a more fragile zona pellucida [19], differences in intercellular communication [10], and a higher incidence of chromosomal abnormalities [72, 82]. All of these factors may contribute to the higher sensitivity to cryoinjury exhibited by IVP embryos.

However, the causes behind these differences are unknown. It is unclear which parts of the process of embryo production are important in determining such parameters as blastocyst yield and blastocyst quality. 


\section{OOCYTE MATURATION IN VIVO VS. IN VITRO}

There is evidence in the literature to suggest that oocytes matured in vivo are more developmentally competent than those matured in vitro. The oocyte undergoes significant modulations in the dominant follicle that play a key role in the acquisition of developmental competence. A number of ultrastructural and molecular changes occurring during oocyte development have been linked to developmental competence [5, 34]. Also, in vitro maturation has been associated with certain abnormalities in the oocyte [31-33].

Assey et al. [4] reported that bovine oocytes aspirated from dominant follicles before the LH surge display alterations in their nuclear and cytoplasmic morphology, which, according to the authors, are a prerequisite for the acquisition of full developmental competence. This would indicate that not only final oocyte maturation (i.e., the processes occurring between LH surge and ovulation) is significant, but also the period preceding the LH surge may be important for the establishment of developmental competence.

We carried out an experiment to evaluate the importance of the events surrounding oocyte maturation [68]. Four groups of oocytes were used: (1) immature oocytes from 2-6-mm follicles from slaughterhouse ovaries, $n=388$; (2) immature oocytes from $>$ 6-mm follicles from slaughterhouse ovaries, $n=99$; (3) immature oocytes recovered in vivo by ovum pick up (OPU) just before the LH surge, $n=102$, and (4) in vivo matured oocytes recovered by OPU, $n=134$. Following recovery, Groups $1-3$ were submitted to IVM for $24 \mathrm{~h}$, while Group 4 oocytes were immediately inseminated. The experimental design was such that oocytes from all 4 groups were inseminated at the same time.

There was no difference in oocyte cleavage rate following IVF; however, significantly more blastocysts developed from oocytes matured in vivo $(58.2 \%)$ than those recovered just before the LH surge $(39.2 \%)$ or those from $2-6-\mathrm{mm}$ follicles $(38.9 \%)$. Oocytes from large follicles ( $>6-\mathrm{mm}$ ) resulted in an intermediate blastocyst yield $(46.5 \%)$. In terms of blastocyst quality (Fig. 1), survival following vitrification was relatively low in all groups ranging from $<40 \%$ at $24 \mathrm{~h}$ post warming to $<20 \%$ in all groups by $72 \mathrm{~h}$ post-warming.

These results clearly demonstrate that oocytes matured in vivo are more competent than those matured in vitro. This in agreement with several previous studies [11, $26,45,52,80]$. The data also support the notion that oocytes derived from large follicles are more competent than those derived from small follicles following IVP [46, 61]. In addition, the data demonstrate that blastocyst quality is unrelated to source of oocyte.

Differences have been reported between in vivo- and in vitro-matured oocytes which may explain the observed differences in developmental competence. Cumulus expansion is usually more extensive following maturation in vivo [75]. In addition, there is a high degree of homogeneity amongst oocytes matured in vivo at the ultrastructural level; this contrasts with the ultrastructural heterogeneity exhibited by in vitro matured oocytes, even when a uniform population of the latter is selected prior to in vitro maturation [17].

\section{OOCYTE FERTILIZATION IN VIVO VS. IN VITRO}

There are few reports in the literature comparing fertilization in vivo versus in vitro. In an experiment designed to assess the importance of fertilization in vitro or in vivo on subsequent blastocyst development and quality, in vivo matured oocytes were either (1) recovered by OPU just prior to ovulation and fertilized in vitro $(n=134)$ or (2) fertilized in vivo by artificial insemination 
Development

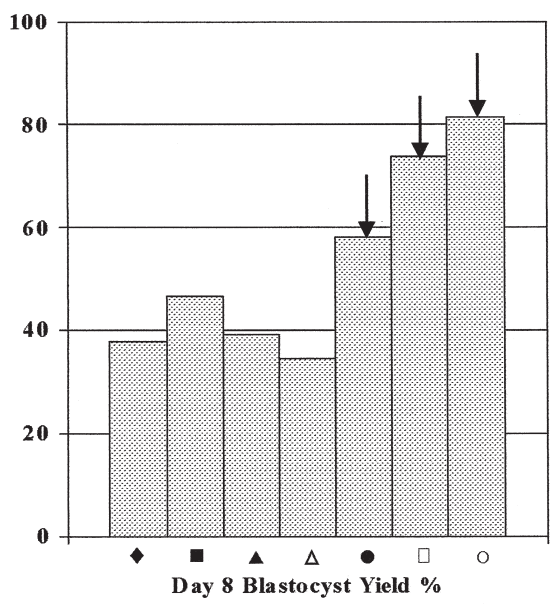

- In vitro 2-6 mm $\Delta \mathrm{IVM} / \mathrm{IVF} /$ Ewe oviduct
- In vitro $>6 \mathrm{~mm}$ $\square$ In vivo matured/fertilized
Quality

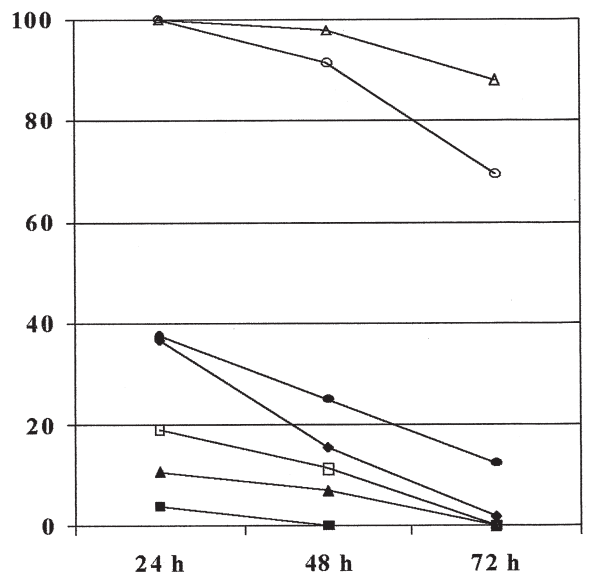

^ Before LH surge

- In vivo matured o In vivo matured/fertilized/cultured

Figure 1. Summary graph of all the data from the 3 experiments relating to oocyte quality measured in terms of blastocyst development, and blastocyst quality measured in terms of survival following vitrification. Blastocysts were derived from oocytes (1) from slaughterhouse ovaries from 2-6 $\mathrm{mm}$ or (2) $>6 \mathrm{~mm}$ follicles, (3) recovered by ovum pick up just prior to the expected time of the LH surge, or (4) following maturation in vivo, (5) matured and fertilized in vitro and cultured in the ewe oviduct, (6) matured/fertilized in vivo and cultured in vitro, or (7) matured/fertilized/cultured in vivo. Arrows indicate that the further along the developmental axis the oocyte/embryo is removed from the in vivo environment the greater the blastocyst development in vitro. In addition, embryo culture in vivo, irrespective of the origin of the oocyte, results in blastocysts of superior quality to culture in vitro.

and the resulting presumptive zygotes surgically recovered on Day $1(n=69)$. Both groups were then cultured in vitro in parallel. As a control, a group of oocytes $(n=388)$ recovered from 2-6-mm follicles from the ovaries of slaughtered heifers were put through IVM/IVF/IVC at the same time.

There was no difference in cleavage rate when in vivo matured oocytes were fertilized in vivo $(92.8 \%)$ or in vitro $(87.3 \%)$. In vivo fertilized oocytes had a significantly higher blastocyst yield $(P<0.01)$ than both in vitro fertilized groups $(73.9 \%$ vs. $58.2 \%$ and $39.2 \%$, for in vivo fertilized, in vivo matured/in vitro fertilized and in vitro matured/in vitro fertilized oocytes, respectively). In addition, in vivo matured/in vitro fertilized oocytes yielded significantly more blastocysts $(P<0.001)$ than in vitro matured oocytes. In terms of blastocyst quality, survival and hatching rate following vitrification was not different between the groups, with survival ranging from $<40 \%$ at $24 \mathrm{~h}$ to $<20 \%$ at $72 \mathrm{~h}$ post warming, suggesting that site of fertilization is not a determining factor of blastocyst quality.

The results of this experiment in which a higher proportion of in vivo matured oocytes developed to blastocysts following fertilization in vivo compared with fertilization in vitro suggests that the events around the time of fertilization might be important in determining the developmental competence of the oocyte. However, whether or not fertilization in vivo per se was solely responsible for the observed increase in blastocyst 
yield is questionable. It should be noted that the in vivo fertilized oocytes were ovulated oocytes; this is in contrast to the in vivo matured/in vitro fertilized group, in which oocytes were recovered from preovulatory follicles just prior to the expected time of ovulation. In unstimulated cattle, ovulation occurs approximately $24 \mathrm{~h}$ after the $\mathrm{LH}$ peak, while following superovulation ovulations occur from 24-33 h after the peak [13]. This would suggest that a proportion of the oocytes removed from preovulatory follicles may not have completed maturation and this may have contributed to a lower blastocyst yield.

To address this question we attempted the fertilization of in vitro matured bovine oocytes in the sheep oviduct using GIFT, involving the transfer of matured oocytes and sperm to the oviduct simultaneously, or the transfer of matured oocytes to the oviduct of a ewe previously inseminated with bovine sperm (results not shown). Irrespective of the method used, only a very low proportion of oocytes were fertilized and none developed to blastocysts. Other authors have similarly attempted the in vivo fertilization of in vitro matured bovine oocytes in the inseminated rabbit [30, 73, 79], sheep [73] and cow oviduct [58, 60, 79] with limited success, although Newcomb et al. [60] did report the birth of twin calves following one such attempt. It would seem that such an approach is fraught with technical difficulties which only cloud the issue.

\section{EMBRYO CULTURE IN VIVO VS. IN VITRO}

In vivo, the oviduct is the site of fertilization and early embryo development. The oviductal environment can support embryonic growth up to the blastocyst stage across a wide range of species following transspecies transfer. Ligated rabbit oviducts have been used extensively for the development of embryos from many species including sheep [6, 43], cattle [9, 20, 74], pigs [63], and horses [3]. Sheep oviducts have been shown to support the growth of cow [22, 23, 25, 27] and pig [65] embryos. The mouse oviduct has also been used to support the development of zygotes from the cow $[39,70]$ and hamster [56].

We carried out two experiments to assess the impact of the culture in vitro or in vivo on the yield and quality of blastocysts. In the first, presumptive zygotes produced by IVM/IVF were cultured either in vitro in synthetic oviduct fluid $(n=463)$, or in vivo in the ewe oviduct $(n=775)$. The cleavage rate of in vitro cultured zygotes was $82.5 \%$; a figure for the cleavage rate of in vivo cultured zygotes was not obtainable due to the degeneration of non-developing embryos in the oviduct. However, there was no difference in the proportion of oocytes developing to the blastocyst stage between the two culture systems (34.1 vs. $34.5 \%)$ ). In contrast, there was a marked difference in the quality of the blastocysts produced in the two culture systems; following vitrification and warming, significantly more blastocysts $(P<0.001)$ from the ewe oviduct survived at all time points and hatched than their in vitro counterparts ( 88.0 vs. $5.6 \%$ survival, respectively at $72 \mathrm{~h}$ ). This would suggest that the culture system is critical in determining blastocyst quality.

The observation that blastocyst yield from IVM/IVF oocytes was unaffected irrespective of whether culture took place in vitro or in vivo in the ewe oviduct is consistent with a previous report from our group [22]. Jimenez et al. [35] observed that culture in the ligated sheep oviduct resulted in similar blastocyst yields to culture in vitro (26 vs. 27\%). However, if ligation was not carried out and the embryos were allowed to go into the uterus, development was significantly reduced [35]. This observation is diffcult to reconcile with the results of Rexroad and Powell [67] and Talbot et al. [76] who demonstrated that the uterus of the ewe supports normal development of bovine blastocysts after transfer at Day 7 
and recovery at Day 14, demonstrating that bovine embryos can undergo continued development in the reproductive tract of ewes when transferred either as 4-cell embryos or as expanded or hatched blastocysts.

In the second experiment, in vivo matured/in vivo fertilized zygotes were either surgically recovered on Day 1 and cultured in vitro in synthetic oviduct fluid $(n=69)$, or remained in vivo and were nonsurgically recovered on Day $7(n=70)$. As a control, a group of zygotes $(n=388)$ produced by IVM/IVF were cultured in vitro in parallel. The cleavage rate and blastocyst yield of in vivo produced zygotes was unaffected by the site of culture (in vitro vs cow oviduct). In addition, both in vivo groups resulted in significantly higher cleavage $(P<0.05)$ and blastocyst yield $(P<0.001)$ at all time points than the in vitro control. In terms of blastocyst quality, as in the first experiment, it was clear that culture system had a dramatic effect on survival following vitrification; in vitro culture, irrespective of origin of the zygote, resulted in significantly lower survival and hatching $(P<0.001)$ than culture in vivo $(69.6 \%$ vs. $0 \%$ and $1.8 \%$ survival at $72 \mathrm{~h}$, for in vivo matured/ fertilized/cultured, in vivo matured/fertilized/in vitro culture and in vitro matured/ fertilized/cultured embryos, respectively).

While culture of IVM/IVF zygotes in the ewe oviduct did not affect blastocyst yield, the oviduct environment of the intermediate recipient clearly improved the overall quality of IVM/IVF blastocysts, as measured by survival following cryopreservation. Similarly, the in vitro culture of zygotes derived from oocytes of high developmental potential (in vivo matured/fertilized) is sufficient to result in blastocysts of low cryotolerance, similar to those resulting from IVM/IVF/IVC. Consistent with these and previous results from our group [22], Pugh et al. [66] observed that culture of bovine embryos in the sheep oviduct improved the frozen but not the fresh embryo survival following transfer. Tervit et al. [77] found that, while culture in the oviduct did not affect the proportion of sheep embryos judged to be of freezeable quality, the percentage of embryos surviving post thaw was higher for IVM/IVF embryos after culture in the oviduct than culture in SOF. Holm et al. [29] demonstrated that IVC of IVM/IVF derived ovine zygotes reduced embryo viability by 15 to $25 \%$ compared with in vivo culture. Galli and Lazzari [25] reported that there were no differences between culture in the ewe oviduct or culture in vitro in terms of blastocyst formation at Day 8. However, in agreement with our results, they observed major differences in quality with embryos cultured in the ewe oviduct and those collected from superovulated donors being superior in terms of sensitivity to freezing/thawing.

The combined results of these two culture experiments provides further evidence that the intrinsic quality of the oocyte determines the blastocyst yield, where in vitro matured/fertilized oocytes resulted in a blastocyst yield of approximately 35\% irrespective of whether they were cultured in vitro or in vivo, while $>70 \%$ of in vivo matured/fertilized oocytes reached that stage following culture either in vitro or in vivo. These results clearly demonstrate that the proportion of oocytes developing to the blastocyst stage is not determined by the culture system, but rather by the origin of the oocytes. In addition, it is clear that oocytes from a common source will result in similar blastocyst development even when culture takes place in different environments.

\section{WHAT CONTROLS THE DEVELOPMENT OF A BLASTOCYST OF HIGH QUALITY?}

Differences have been described at the ultrastructural level which may in part explain the variation in cryotolerance observed amongst groups of embryos. In a recent study from our group [24] it was 
demonstrated that blastocysts derived from the in vivo culture in the ewe oviduct of IVM/IVF zygotes displayed only minor morphological differences from those produced completely in vivo by superovulation. In contrast, in vitro produced blastocysts exhibited a range of characteristics associated with reduced cryotolerance such as vacuoles in the trophoblast cells, a sparse population of microvilli, a greatly reduced network of intercellular connections and a large increase in lipid content. Similar observations have been reported by other authors $[2,16]$.

Differences in gene expression exist between in vitro- and in vivo-derived embryos which may explain the differences in quality observed. Wrenzycki et al. [85] demonstrated that expression of the connexin 43 gene at the blastocyst stage differs between bovine embryos produced in vitro and those produced in vivo. This gene is involved in the formation of a protein that gives rise to gap junctions between cells. Poor gap junction formation is associated with poor cell compaction and is a common occurrence in IVP embryos. Also, accelerated development in vitro due to serum addition $[14,49]$ may affect gene regulation and transcription, resulting in well-documented developmental abnormalities such as foetal oversize in the bovine [88].

It has also been demonstrated that the gene expression in the developing embryo can be influenced by the culture environment in vitro [36, 44, 59, 86]. Knijn et al. [38] compared gene expression in blastocysts derived from in vivo- or in vitro matured bovine oocytes. No differences were observed in relative abundance for 4 genes studied, suggesting that maturation is not the major step in the IVP process affecting expression of these genes in the embryo. This would be consistent with the findings of Wrenzycki et al. [86] and those of the present study, reinforcing the point that the culture system is the major determinant of blastocyst quality, irrespective of the origin of the oocyte.
The culture environment can also have a significant effect on embryo metabolism which may have implications for embryo quality. Embryos generated in a completely defined medium have lower rates of glycolysis than those in serum [40]. Khurana and Niemann [37] examined energy metabolism in in vivo- and in vitro-derived bovine embryos. In general, the pattern was similar; however, IVP embryos exhibited a 2 -fold higher rate of anaerobic glycolysis and produced more lactate. Culture for $72 \mathrm{~h}$ of in vivo-produced blastocysts resulted in lactate production similar to that of in vitro produced blastocysts.

\section{CONCLUSION}

Events before ovulation determine the ultimate fate of the oocyte but events occurring between the zygote and blastocyst stages determine the blastocyst quality. As pointed out by Hendriksen et al. [28], the observation that oocytes with identical developmental conditions up to the LH surge (i.e. initiation of meiotic resumption) differ in their ability to reach the blastocyst stage depending on whether they undergo maturation in vivo or in vitro highlights the fact that current in vitro maturation methods can still be improved. One route towards improving embryo yield may be the prematuration of the oocyte prior to maturation. While some recent results are encouraging in that oocytes can be reversibly maintained at the germinal vesicle stage without affecting subsequent blastocyst yield $[41,47,50,55,57]$, it has not yet been demonstrated that such an approach can improve the developmental ability of an oocyte. In addition, there is little if any evidence to demonstrate that such blocked oocytes can result in the birth of normal offspring. A more feasible approach in the short term at least will probably be to modify the conditions of in vitro culture to ensure that those blastocysts that do develop are of the highest possible quality. 


\section{ACKNOWLEDGMENTS}

This work was partly financed by the EU Commission (QLK3-CT-1999-00104). D. Rizos was supported by a grant from the Greek state Scholarships Foundation. We thank M. Wade for excellent technical assistance and T. Harte and the staff at Lyons for help in maintaining the animals.

\section{REFERENCES}

[1] Abd El Razek I.M., Charpigny G., Kodja S., Marquant-Le Guienne B., Mermillod P., Guyader-Joly C., Humblot P., Differences in lipid composition between in vivo- and in vitroproduced bovine embryos, Theriogenology 53 (2000) 346 abstract.

[2] Abe H., Yamashita S., Itoh T., Satoh T., Hoshi H., Ultrastructure of bovine embryos developed from in vitro-matured and -fertilized oocytes: comparative morphological evaluation of embryos cultured either in serum-free medium or serum-supplemented medium, Mol. Reprod. Dev. 53 (1999) 325-335.

[3] Allen W.R., Stewart F., Trounson A.O., Tischner M., Bielanski W., Viability of horse embryos after storage and long distance transport in the rabbit, J. Reprod. Fertil. 47 (1976) 387-390.

[4] Assey R.J., Hyttel P., Greve T., Purwantara B., Oocyte morphology in dominant and subordinate follicles, Mol. Reprod. Dev. 37 (1994) 335-344.

[5] Assey R.J., Hyttel P., Roche J.F., Boland M., Oocyte steroid and follicular steroid concentrations in superovulated versus unstimulated heifers, Mol. Reprod. Dev. 39 (1994) 8-16.

[6] Averill R.L.W., Adams C.E., Rowson L.E.A., Transfer of mammalian ova between species, Nature 176 (1955) 167-170.

[7] Bavister B.D, Culture of preimplantation embryos: facts and artifacts, Hum. Reprod. Update 1 (1995) 91-148.

[8] Bavister B.D., Boatman D.E., Leibfried M.L., Loose M., Vernon M.W, Fertilization and cleavage of rhesus monkey oocytes in vitro, Biol. Reprod. 28 (1983) 983-999.

[9] Boland M.P., Use of the rabbit oviduct as a screening tool for the viability of mammalian eggs, Theriogenology (1984) 126-137.

[10] Boni R., Tosti E., Roviello S., Dale B., Intracellular communication in in vivo- and in vitroproduced bovine embryos, Biol. Reprod. 61 (1999) 1050-1055.

[11] Bordignon V., Morin N., Durocher J., Bousquet D., Smith L.C., GnRH improves the recovery rate and the in vitro developmental competence of oocytes obtained by transvaginal follicular aspiration from superstimulated heifers, Theriogenology 48 (1997) 291-298.

[12] Brevini-Gandolfi T., Favetta L.A., Lonergan P., Gandolfi F, The mechanism regulating maternal mRNA stability and translation is affected in bovine embryos with low developmental competence, Theriogenology 53 (2000) 268 abst.

[13] Callesen H., Greve T., Hyttel P., Preovulatory endocrinology and oocyte maturation in superovulated cattle, Theriogenology 25 (1986) 71-86.

[14] Carolan C., Lonergan P., Van Langendonckt A., Mermillod P., Factors affecting bovine embryo development in synthetic oviduct fluid following oocyte maturation and fertilization in vitro, Theriogenology 43 (1995) 1115-1128.

[15] Comizzoli P., Marquant-Le Guienne B., Heyman Y., Renard J.P., Onset of the first S-phase is determined by a paternal effect during the G1-phase in bovine zygotes, Biol. Reprod. 62 (2000) 1677-1684.

[16] Crosier A.E., Farin P.W., Dykstra M.J., Alexander J.E., Farin C.E., Ultrastructural morphometry of bovine compact morulae produced in vivo or in vitro, Biol. Reprod. 62 (2000) 1459-1465.

[17] de Loos F., van Maurik P., van Beneden T., Kruip T.A., Structural aspects of bovine oocyte maturation in vitro, Mol. Reprod. Dev. 31 (1992) 208-214.

[18] Dinnyes A., Lonergan P., Fair T., Boland M.P, Yang X., Timing of the first cleavage postinsemination affects cryosurvival of in vitroproduced bovine blastocysts, Mol. Reprod. Dev. 53 (1999) 318-324.

[19] Duby R.T., Hill J.L., O'Callaghan D., Overstrom E.W., Boland M.P., Changes induced in the bovine zona pellucida by ovine and bovine oviducts, Theriogenology 47 (1997) 332 abst.

[20] Ectors F.J., Thonon F., Delval A., Fontes R.S., Touati K., Beckers J.F., Ectors F., Comparison between culture of bovine embryos in vitro versus development in rabbit oviducts and in vivo, Livestock Prod. Sci. 36 (1993) 29-34.

[21] Eid L.N., Parrish J.J., Duration of G2-phase and onset of M-phase during the first cell cycle of the bovine embryo is dependent on bull in vivo fertility, Theriogenology (1995) 205 abst.

[22] Enright B.P., Lonergan P., Dinnyes A., Fair T., Ward F.A., Yang X., Boland M.P., Culture of in vitro produced bovine zygotes in vitro vs. in vivo: implications for early embryo development and quality, Theriogenology 54 (2000), 659-673.

[23] Eyestone W.H., Leibfried-Rutledge M.L., Northey D.L., Gilligan B.G., First N.L., Culture of one- and two-cell bovine embryos to the blastocyst stage in the ovine oviduct, Theriogenology 28 (1987) 1-7. 
[24] Fair T., Lonergan P., Dinnyes A., Cottell D., Hyttel P., Ward F.A., Boland M.P., Ultrastructure of bovine blastocysts following cryopreservation: effect of method of embryo production on blastocyst quality, Mol. Reprod. Dev. 58 (2001) 186-195.

[25] Galli C., Lazzari G., Practical aspects of IVM/IVF in cattle, Anim. Reprod. Sci. 42 (1996) 371-379.

[26] Greve T., Xu K.P., Callesen H., Hyttel P., In vivo development of in vitro fertilized bovine oocytes matured in vivo versus in vitro, $\mathrm{J}$. In Vitro Fert. Embryo Transf. 4 (1987) 281-285.

[27] Gutierrez-Adan A., Behboodi E., Anderson G.B., Medrano J.F., Murray J.D., Relationship between stage of development and sex of bovine IVM-IVF embryos cultured in vitro versus in the sheep oviduct, Theriogenology 46 (1996) 515-525.

[28] Hendriksen P.J.M., Vos P.L.A.M., Steenweg W.N.M., Bevers M.M., Dieleman S.J., Bovine follicular development and its effect on the in vitro competence of oocytes, Theriogenology 53 (2000) 11-20.

[29] Holm P., Walker S.K., Petersen B.A., Ashman R.J., Seamark R.F., In vitro vs. in vivo culture of ovine IVM-IVF ova: effect on lambing, Theriogenology 41 (1994) 217 abst.

[30] Hunter R.H.F., Lawson R.A.S., Rowson L.E.A., Maturation, transplantation and fertilization of ovarian oocytes in cattle, J. Reprod. Fertil. 30 (1972) 325-328.

[31] Hyttel P., Xu K.P., Smith S., Greve T., Ultrastructure of in-vitro oocyte maturation in cattle, J. Reprod. Fertil. 78 (1986) 615-625.

[32] Hyttel P., Xu K.P., Greve T., Ultrastructural abnormalities of in vitro fertilization of in vitro matured bovine oocytes, Anat Embryol 178 (1988) 47-52.

[33] Hyttel P., Greve T., Callesen H., Ultrastructural aspects of oocyte maturation and fertilization in cattle, J. Reprod. Fertil. 38 (suppl.) (1989) 35-47.

[34] Hyttel P., Fair T., Callesen H., Greve T., Oocyte growth, capacitation and final maturation in cattle, Theriogenology 47 (1997) 23-32.

[35] Jimenez C., Rumph N., Moore H., Walmsely S., Buckrell B., Pollard J.W., Sheep intermediate recipient culture of in vitro produced bovine embryos: culture in ligated oviducts versus combined oviductal-uterine culture, Theriogenology 55 (2001) 336 abst.

[36] Khosla S., Dean W., Brown D., Reik W., Feil R., Culture of preimplantation mouse embryos affects fetal development and the expression of imprinted genes, Biol. Reprod. 64 (2001) 918-926.

[37] Khurana N.K., Niemann H., Energy metabolism in preimplantation bovine embryos derived in vitro or in vivo, Biol. Reprod. 62 (2000) $847-856$
[38] Knijn H.M., Wrenzycki C., Hendriksen P.J.M., Vos P.L.A.M., van der Weijden G.C., Niemann H., Dieleman S.J., Effects of in vitro versus in vivo maturation on gene expression in single bovine blastocysts, Theriogenology 55 (2001) 238 abst.

[39] Krisher R.L., Petters R.M., Johnson B.H., Bavister B.D., Archibong A.E., Development of porcine embryos from the one-cell stage to blastocyst in mouse oviducts maintained in organ culture, J. Exp. Zool. 249 (1989) 235-239.

[40] Krisher R.L., Lane M., Bavister B.D., Developmental competence and metabolism of bovine embryos cultured in semi-defined and defined culture media, Biol. Reprod. 60 (1999) 1345-1352.

[41] Kubelka M., Motlik J., Schultz R.M., Pavlok A., Butyrolactone I reversibly inhibits meiotic maturation of bovine oocytes without influencing chromosome condensation activity, Biol. Reprod. 62 (2000) 292-301.

[42] Langendonckt A.V., Donnay I., Schuurbiers N., Auquier P., Carolan C., Massip A., Dessy F., Effects of supplementation with fetal calf serum on development of bovine embryos in synthetic oviduct fluid medium, J. Reprod. Fertil. 109 (1997) 87-93.

[43] Lawson R.A.S., Adams C.E., Rowson L.E.A., The development of sheep eggs in the rabbit oviduct and their viability after re-transfer to ewes, J. Reprod. Fertil. 29 (1972) 105-116.

[44] Lee K.F., Chow J.F.C, Xu J.S, Chan S.T.H., Ip S.M., Yeung W.S.B., A comparative study of gene expression in murine embryos developed in vivo, cultured in vitro, and cocultured with human oviductal cells using messenger ribonucleic acid differential display, Biol. Reprod. 64 (2001) 910-917.

[45] Leibfried-Rutledge M.L., Critser E.S., Eyestone W.H., Northey D.L., First N.L., Development potential of bovine oocytes matured in vitro or in vivo, Biol. Reprod. 36 (1987) 376-383.

[46] Lonergan P., Monaghan P., Rizos D., Boland M.P., Gordon I., Effect of follicle size on bovine oocyte quality and developmental competence following maturation, fertilization, and culture in vitro, Mol. Reprod. Dev. 37 (1994) 48-53.

[47] Lonergan P., Khatir H., Carolan C., Mermillod P., Bovine blastocyst production in vitro after inhibition of oocyte meiotic resumption for $24 \mathrm{~h}$, J. Reprod. Fertil. 109 (1997) 355-365.

[48] Lonergan P., Khatir H., Piumi F., Rieger D., Humblot P., Boland M.P., Effect of time interval from insemination to first cleavage on the developmental characteristics, sex and pregnancy rates following transfer of bovine preimplantation embryos, J. Reprod. Fertil. 117 (1999) 159-167.

[49] Lonergan P., O'Kearney-Flynn M., Boland M.P., Effect of protein supplementation and presence of an antioxidant on the development of bovine zygotes in synthetic oviduct fluid medium under high or low oxygen tension, Theriogenology 51 (1999) 1565-1576. 
[50] Lonergan P., Dinnyes A., Fair T., Yang X., Boland M., Bovine oocyte and embryo development following meiotic inhibition with butyrolactone I, Mol. Reprod. Dev. 57 (2000) 204-209.

[51] Lonergan P., Gutierrez-Adan A., Pintado B., Fair T., Ward F.A., de la Fuente J., Boland M.P., Relationship between time of first cleavage and the expression of IGF-I growth factor, its receptor and two housekeeping genes in bovine twocell embryos and blastocysts produced in vitro, Mol. Reprod. Dev. 57 (2000) 146-152.

[52] Marquant-Le Guienne B., Gerard M., Solari A., Thibault C., In vitro culture of bovine egg fertilized either in vivo or in vitro, Reprod. Nutr. Dev. 29 (1989) 559-568.

[53] Massip A., Mermillod P., Dinnyes A., Morphology and biochemistry of in-vitro produced bovine embryos: implications for their cryopreservation, Hum. Reprod. 10 (1995) 3004-3011.

[54] McKiernan S.H., Bavister B.D., Timing of development is a critical parameter for predicting successful embryogenesis, Hum. Reprod. 9 (1994) 2123-2129.

[55] Mermillod P., Tomanek M., Marchal R., Meijer L., High developmental competence of cattle oocytes maintained at the germinal vesicle stage for 24 hours culture by specific inhibition of MPF kinase activity, Mol. Reprod. Dev. 55 (2000) 89-95.

[56] Minami N., Bavister B.D., Iritani A., Development of hamster two-cell embryos in the isolated mouse oviduct in organ culture system, Gamete Res. 19 (1988) 235-240.

[57] Motlik J., Pavlok A., Lapthitis G., Kubelka M., Impact of two-step in vitro culture systems on developmental potency of oocytes, Reprod. Dom. Anim. 35 (2000) 267-271.

[58] Myers M.W., Zhang L., Stroud B.K., Godke R.A., Development of in vitro-matured bovine oocytes fertilized either in vitro or in vivo, in: Proceedings of the 12th Congress on Animal Reproduction, The Hague, 1992, pp. 668-670.

[59] Natale D.R., Kidder G.M., Westhusin M.E., Watson A.J., Assessment by differential display-RT-PCR of mRNA transcript transitions and $\alpha$-amanitin sensitivity during bovine preattachment development, Mol. Reprod. Dev. 55 (2000) 152-163.

[60] Newcomb R., Christie W.B., Rowson L.E.A., Birth of calves after in vivo fertilisation of oocytes removed from follicles and matured in vitro, Vet. Rec. 102 (1978) 461-462.

[61] Pavlok A., Lucas-Hahn A., Niemann H., Fertilization and developmental competence of bovine oocytes derived from different categories of antral follicles, Mol. Reprod. Dev. 31 (1992) 63-67.

[62] Pinyopummintr T., Bavister B.D., Development of bovine embryos in a cell-free culture medium: effects of type of serum, timing of its inclusion and heat inactivation, Theriogenology 41 (1994) 1241-1249.

[63] Polge C., Adams C.E., Baker R.D., Development and survival of pig embryos in the rabbit oviduct, in: 7th International Congress on Animal Reproduction and Artificial Insemination, 1972, pp. 513-517.

[64] Pollard J.W., Leibo S.P., Chilling sensitivity of mammalian embryos, Theriogenology 41 (1994) 101-106.

[65] Prather R.S., Sims M.M., First N.L., Culture of porcine embryos from the one- and two-cell stage to the blastocyst stage in sheep oviducts, Theriogenology 35 (1991) 1147-1151.

[66] Pugh A., Cox S., Peterson J., Ledgard A., Forsyth J., Cockrem K., Tervit R., Culture of bovine embryos in sheep oviducts improves frozen but not fresh embryo survival, Theriogenology 55 (2001) 314 abst.

[67] Rexroad C.E., Powell A.M., The ovine uterus as a host for in vitro-poduced bovine embryos, Theriogenology 52 (1999) 351-364.

[68] Rizos D., Ward F., Duffy P., Boland M.P., Lonergan P., Consequences of bovine oocyte maturation, fertilization or early embryo development in vitro versus in vivo: implications for blastocyst yield and blastocyst quality, Mol. Reprod. Dev. 61 (2002) 234-248.

[69] Sakkas D., Shoukir Y., Chardonnens D., Bianchi P.G., Campana A., Early cleavage of human embryos to the two-cell stage after intracytoplasmic sperm injection as an indicator of embryo viability, Hum. Reprod. 13 (1998) 182-187.

[70] Sharif H., Vergos E., Lonergan P., Gallagher M., Kinis A., Gordon I., Development of early bovine embryos in the isolated mouse oviduct maintained in organ culture, Theriogenology 35 (1991) 270 abst.

[71] Shoukir Y., Chardonnens D., Campana A., Bischof P., Sakkas D., The rate of development and time of transfer play different roles in influencing the viability of human blastocysts, Hum. Reprod. 13 (1998) 676-681.

[72]. Slimane W., Heyman Y., Lavergne Y., Humblot P., Renard J.P., Assessing chromosomal abnormalities in two-cell bovine in vitro fertilized embryos by using in situ hybridization with three different cloned probes, Biol. Reprod. 62 (2000) 628-635.

[73] Sreenan J., In vitro maturation and attempted fertilization of cattle follicular oocytes, J. agric. Sci., Camb. (1970) 393-396.

[74] Sreenan J.M., Scanlon P., Gordon I., Culture of fertilised cattle eggs, J. Agric. Sci. 70 (1968) 183-185.

[75] Suzuki H., Presicce G.A., Yang X, Analysis of bovine oocytes maturated in vitro vs in vivo by scanning electron microscopy, Theriogenology 45 (1996) 271 abst. 
[76] Talbot N.C., Powell A., Garrett W., Edwards J.L., Rexroad C. Jr., Ultrastructural and karyotypic examination of in vitro produced bovine embryos developed in the sheep uterus, Tissue Cell 32 (2000) 9-27.

[77] Tervit H.R., Pugh P.A., McGowan L.T., Bell A.C.S., Wells R.W., The freezability of sheep embryos is affected by culture system and source (in vivo or in vitro derived), Theriogenology 41 (1994) 315 abst.

[78] Totey S.M., Daliri M., Rao K.B.C.A., Pawshe C.H., Taneja M., Chillar R.S., Differential cleavage and developmental rates and their correlation with cell numbers and sex ratios in buffalo embryos generated in vitro, Theriogenology 45 (1996) 521-533.

[79] Trounson A.O., Willadsen S.M., Rowson L.E.A., Fertilization and development capability of bovine follicular oocytes matured in vitro and in vivo and transferred to the oviducts of rabbits and cows, J. Reprod. Fert. 51 (1977) 321-327.

[80] van de Leemput E.E., Vos P.L.A.M., Zeinstra E.C., Bevers M.M., van der Weijden G.C., Dieleman S.J., Improved in vitro embryo development using in vivo matured oocytes from heifers superiovulated with a controlled preovulatory LH surge, Theriogenology 52 (1999) 335-349.

[81] Van Soom A., Vlaenderen I.V., Mahmoudzadeh A.R., Deluyker H., de Kruif A., Compaction rate of in vitro fertilized bovine embryos related to the interval from insemination to first cleavage, Theriogenology 38 (1992) 905-919.

[82] Viuff D., Rickords L., Offenberg H., Hyttel P., Avery B., Greve T., Olsaker I., Williams J.L.,
Callesen H., Thomsen P.D., A high proportion of bovine blastocysts produced in vitro are mixoploid, Biol. Reprod. 60 (1999) 1273-1278.

[83] Ward F., Rizos D., Corridan D., Quinn K.M., Boland M.P, Lonergan P., Paternal influence on the time of the first embryonic cleavage post insemination and the implications for subsequent bovine embryo development in vitro and fertility in vivo, Mol. Reprod. Dev. 60 (2001) 47-55.

[84] Warner C.M., McElhinny A.S., Wu L., Cieluch C., Ke X., Cao W., Tang C., Exley G.E., Role of the Ped gene and apoptosis genes in control of preimplantation development, J. Assist. Reprod. Genet. 15 (1998) 331-337.

[85] Wrenzycki C., Herrmann D., Carnwath J.W., Niemann H., Expression of the gap junction gene connexin $43(\mathrm{C} \times 43)$ in preimplantation bovine embryos derived in vitro or in vivo, J. Reprod. Fertil. 108 (1996) 17-24.

[86] Wrenzycki C., Herrmann D., Carnwath J.W., Niemann H., Alterations in the relative abundance of gene transcripts in preimplantation bovine embryos cultured in medium supplemented with either serum or PVA, Mol. Reprod. Dev. 53 (1999) 8-18.

[87] Wright R.W., Ellington J., Morphological and physiological differences between in vivo- and in vitro-produced preimplantation embryos from livestock species, Theriogenology 44 (1995) 1167-1189.

[88] Young L.E., Sinclair K.D., Wilmut I., Large offspring syndrome in cattle and sheep, Rev. Reprod. 3 (1998) 155-163.

To access this journal online: www.edpsciences.org 